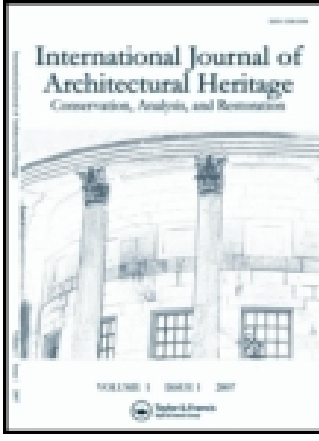

International Journal of Architectural Heritage

Conservation, Analysis, and Restoration

ISSN: 1558-3058 (Print) 1558-3066 (Online) Journal homepage: http://www.tandfonline.com/loi/uarc20

\title{
Dampness Problems in a Historic House in İzmir, Turkey
}

\section{Bülent Yardım \& S. Sarp Tunçoku}

To cite this article: Bülent Yardım \& S. Sarp Tunçoku (2008) Dampness Problems in a Historic House in İzmir, Turkey, International Journal of Architectural Heritage, 3:1, 1-23, DOI: $\underline{10.1080 / 15583050701842385}$

To link to this article: http://dx.doi.org/10.1080/15583050701842385

册 Published online: 26 Nov 2008.

Submit your article to this journal $\sqsubset \pi$

Џلll Article views: 129

Q View related articles $₫$

4 Citing articles: 6 View citing articles 


\title{
DAMPNESS PROBLEMS IN A HISTORIC HOUSE IN IZMIR, TURKEY
}

\author{
Bülent Yardım and S. Sarp Tunçoku \\ ${ }^{1}$ Architect, İzmir, Turkey \\ ${ }^{2}$ Department of Architectural Restoration, Faculty of Architecture, Izmir \\ Institute of Technology (IYTE), Urla, İzmir, Turkey
}

The study, as a preliminary stage of the restoration work of a historic house from Levantine ages of Izmir in the nineteenth century, involves the examination of the dampness basement problems. Moisture contents and temperature of the wall surfaces were monitored by nondestructive techniques, such as direct measurements of electrical conductivity and infrared thermography. The results were evaluated in the light of physical properties, moisture, and soluble salt types and contents in the materials, outdoor, and indoor climatic conditions, layout of the site, and architectural features of the building. In addition to rising damp and lack of sufficient ventilation for years, some faulty details along the intersections with the terraces of the neighbor buildings, and intersection with the asphalt coated street and the basement windows that gave way for rainwater leaks were the other sources of dampness. Some cool but relatively dry parts of the walls were found to be potential zones for dampness problem through condensation between midnight and early mornings, especially in winter.

KEY WORDS: dampness, moisture, infrared thermography (IRT), historic masonry

\section{INTRODUCTION}

Most of historic buildings at present have undergone various destructive effects of nature, such as the weathering of materials and damage caused by earthquakes, flood, lightning, storms, and landslides as well as effects caused by man. Much of the harm is also caused during the reuse of the buildings and inadequate interventions underestimating the original construction techniques, materials, and their present situations.

The study aimed to investigate the existence and possible sources of the dampness in a historic building, the Nebahat Tabak Residence in the Basmane District as an initial stage for its restoration. This place was the vivacious commercial center of Izmir in Levantine Period until the end of the nineteenth century (Yardim, 2006). İzmir, located at the Aegean Coast of Anatolia, called Smyrna in ancient times was one of the most strategically important and attractive cities throughout the Mediterranean history (Figure 1).

Received 15 March 2007; accepted 2 November 2007.

Address correspondence to S. Sarp Tunçoku, Department of Architectural Restoration, Faculty of Architecture, İzmir Institute of Technology (IYTE), Gülbahçe, Urla 35430/İzmir/Turkey. E-mail: sarptuncoku@iyte.edu.tr 


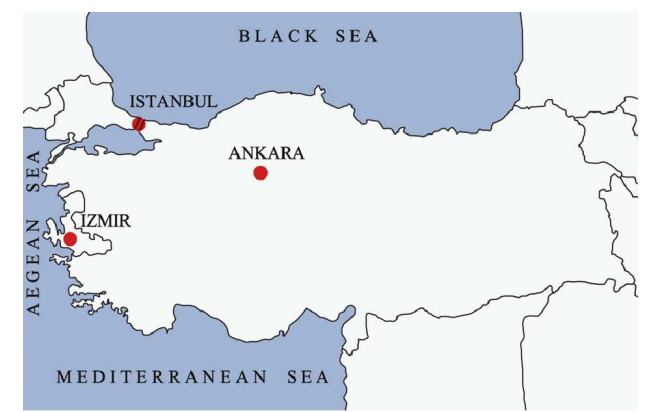

[a]

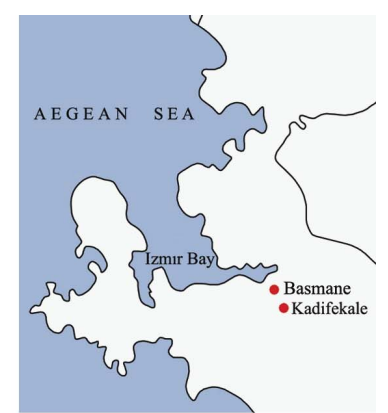

[b]

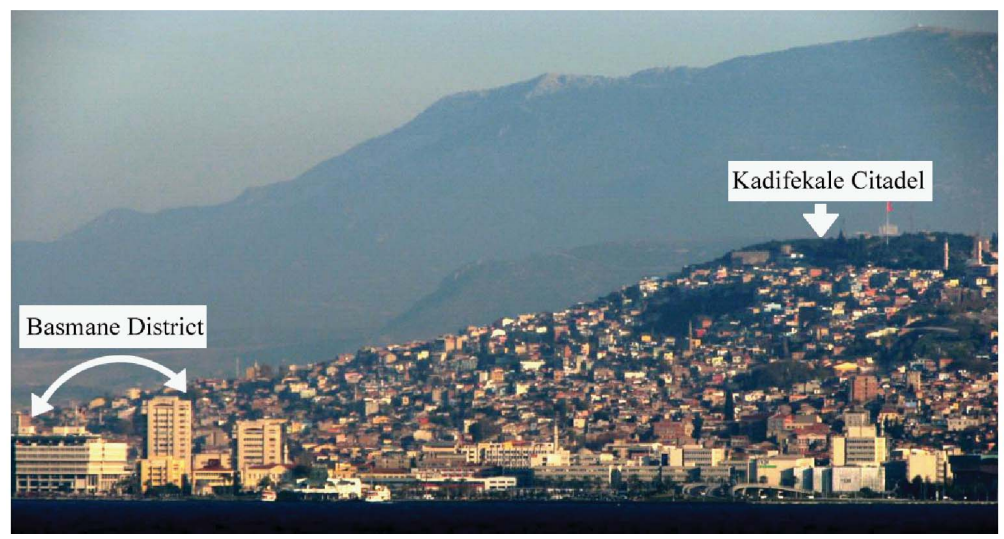

[c]

Figure 1. A) Map of the location of İzmir City, Turkey, and approximate position of B) Kadifekale Citadel and C) Basmane District viewed from İzmir Bay (figure is provided in color online).

Compared with the central and eastern parts, the Aegean Coast of Anatolia possesses milder climate. Despite the relatively short and mild winter, İzmir has been suffering air pollution problems in the recent years. Pollution has become particularly problematic during winter nights due to the consumption of insufficient energy sources for heating primarily in dwelling buildings since their number rapidly increased around the downtown in the past decade. The combined effects of the humid atmosphere, which is endemic to the region, and polluted air have been observed in varying forms of deterioration on the porous building materials of historic monuments in the city.

The area where the study was carried out contained numerous residences that once belonged to the noble families and merchants that were lined up on both sides of the narrow streets on the order of attached-pattern. They were all typical to the Levantine Period of İzmir. Despite some changes in time, the area still reflects the architectural characteristics of the period (Figure 2).

The exact construction date of the Tabak House is unknown, but it is thought to have been built in the second half of the nineteenth century based on comparison of its architectural features and workmanship with other houses for which the construction dates are known. It was seriously damaged due to its abandonment since the 1970s. A partially collapsed roof and loss of the most of the windows and doors in the upper floors caused the house to be entirely open to outdoor conditions giving way for further damages by the direct penetration of rainwater and wind, as well as polluted air. 


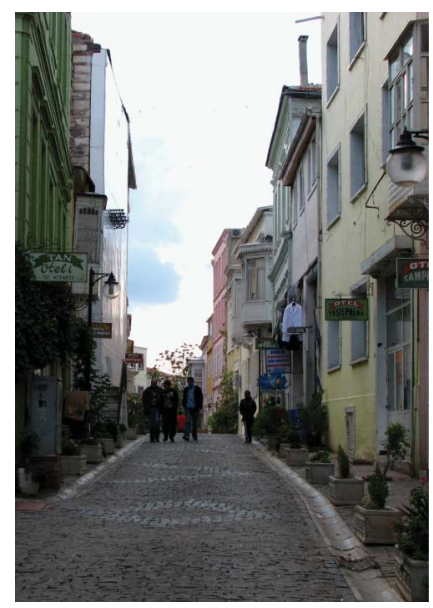

[a]

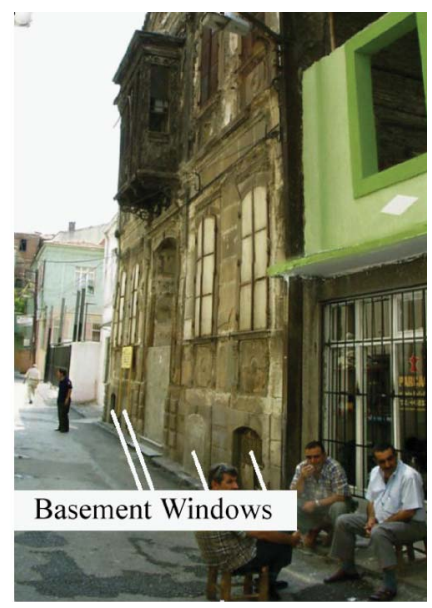

[b]

Figure 2. Photographs of the views from A) the street of hotels and B) the street \#1299 and Tabak House

Despite a few holes found on its blind-metal windows, the basement seemed to be protected against outdoor conditions better than the upper floors. Therefore, dampness survey is limited with the basement where the humidity was detected, but the cause was not certain.

\subsection{Method}

Due to the heterogeneous character and the thickness of the walls, the difficulties inherent in a thorough estimation of moisture content in masonry structures are well known. Especially in the case of historic buildings, which involve many complicated and combined parameters while not allowing material sampling in sufficient quantity and invasive test techniques, such an estimation becomes more difficult. However, owing to the developments in nondestructive or slightly destructive test techniques in the recent years, it is possible to carry out diagnostic studies and surveys in a relatively short time. Among these techniques, infrared thermography (IRT) (Grinzato et al., 1998; 2002; Balaras and Argirou, 2002; Avdelidis and Moropoulou, 2004; Barreira and Freitas, 2007) impulse or ground penetration radar (Moropoulou et al., 2002), microwave (Binda et al., 1998; Kääriänen et al., 2001) and ultrasonic velocity (UV) measurements (Grinzato et al., 2004), and measurements of electrical conductivity, particularly in wood (Quarles, 2008) are those mostly employed in building and site investigations (Wirahadikusumah et al., 1998; Wiggenhauser, 2002; Clark et al., 2003; Meola et al., 2005).

The emergency nature of the restoration of the Tabak House, limited the time for determination of which techniques to use for a quick survey to detect the level and the possible sources of the dampness in the basement. In addition to the detection of indoor climatic conditions, the decision was made to perform IRT and conductometric moisture measurement. 
An infrared camera measures the thermal radiation emitted from the material and displays the scanned-surface as a colored or gray image, the tones that correspond to the gradation in temperature. In case of dampness, cooler areas where evaporation (an endothermic reaction cooling the surface) occurs, represent the moistened parts of the surface (Grinzato et al., 1998; 2002; Balaras and Argirou, 2002; Avdelidis and Moropoulou, 2004; Barreira and Freitas, 2007). However, in addition to the material properties, the existence of excessive relative humidity and/or carbon dioxide in the ambient air also affects the results of thermographic measurements (Avdelidis and Moropoulou, 2003; Avdelidis et al., 2003). Such interferences can be eliminated by extended thermography through specific filters with different detection bands (called selective IRT [infrared thermography], as noted previously) to be supplemented with material analyses. A similar technique is also proved to be used for hygroscopic salts (having high equilibrium moisture) through laboratory analyses for the estimation of real moisture conditions in terms of condensation, saturation and their precipitation in the material which cause damage to the structure (Gayo-Monco and Frutos, 1997;1998).

Surface temperatures of the walls were recorded by using a FLIR ThermaCAM PM695 infrared camera (FLIR Systems, Boston, MA, USA). It has un-cooled micro bolometer type detector of $320 \times 240$ pixels in focal plane array and thermal sensitivity of $0.08^{\circ} \mathrm{C}$, with a spectral range of $7.5-13 \mu \mathrm{m}$. The emissivity of stone walls was assumed to be 0.90 for the survey. ThermaCAM Reporter 2000 Professional and ThermaCAM Explorer 99 Software (FLIR Systems, Boston, MA, USA) were used for creating the thermal images of wall surfaces.

The moisture readings were performed on the wall surfaces by using the GE Protimeter Surveymaster (GE Inspection \& Sensing Technologies, Buckinghamshire, England) developed as a non-destructive testing device to measure moisture content in wood by electrical conductance. It also gives a wood-moisture-equivalent in other materials with an approximate measurement-depth of 0.5 inch from the surface. Wood moisture equivalent represents the theoretical level of moisture content expressed in percentage that would be attained by a piece of wood in contact with the material under investigation. The lowest decay-safety level of the moisture content of wood at $75 \%-80 \%$ relative humidity is in the range of $16 \%-20 \%$ in mass, below which the wood is supposed to be dry (Coleman, 1999). In this study, the limit of the wood-moisture equivalent for the level of dry zone is assumed to be $20 \%$. As mentioned previously, the technique has an important disadvantage in terms of assessing hygroscopic salts with high conductivity which displays excessive moisture content misleadingly (Coleman, 1999; 2000). For this reason, other than the consideration of each measured value, the differentiations in the values are utilized to obtain a qualitative and relative moisture distribution on the walls.

In addition to IRT, the moisture survey is also extended with the laboratory analyses for the determination of the physical properties, actual moisture and soluble salt contents and types found in the materials from the walls, and indoor/outdoor climatic data to be discussed and evaluated to have information as close as possible to the real moisture conditions in the basement.

The indoor climatic conditions, such as the air temperature, dew point temperature, relative humidity and air flow were determined by thermal and hygric measurements on the same survey days (September 23 and December 2, 2005) when the conductometric moisture measurements and IRT scanning of the walls were performed. The outdoor climate data of the years 2004 and 2005 deemed as the recent 
history of the climate was also used to examine the likely effects of the environmental conditions on the dampness problem.

The relationships between the street, garden and neighbor buildings adjacent to the Tabak House on its north and south sides, the buildings facing the house across the narrow street, and the topography of the nearby surroundings were the other concerns considered within the overall evaluation of the survey and experimental results.

\subsection{Architectural and Constructional Features of the Building}

1.2.1. The Site The Tabak House was accessed from the west edge of a narrow lane, numbered 1299 and opened to Oteller Sokă̌l which referred to the street of hotels. In fact, almost all hotels were originally the houses that were built in the nineteenth century, the Levantine ages of Izmir. These houses were converted into hotels in the past few decades (Figures 2 and 3). In general, all hotels around the area have served for lower income-peoples and migrants who are seeking a job in the city.

The house, which was situated on the northeast side of the courtyard, comprises three stories including the basement (Figures 2B and 3).

There were three service buildings in the courtyard built during 1960s when the house was donated by the Tabak Family to be used as a dormitory for the orphans. The first service building is a two-story building at the southeast edge of the courtyard with an independent entrance through a cul-de-sac was that as lodging for the staff. The second building, which was adjacent to the house at its northwest-edge, was composed of a single-story with a bath and toilets for the children who once lived in the dormitory; this building placed between the lodgment building and the house. The third building, separated from the house with the alcove-like basement entrance-niche at the southwest, was also a single-story building and served as the cloth-drying building (Figure 3).

Regarding the missing doors and widows of the main building, this, the unfortunate situation was also true for these buildings. They were entirely open to outdoor conditions. The electrical, potable water and sewage disposal installations were completely damaged. Water and power supply of the house and attached buildings were cut-off by the local municipality since the time of abandonment.

1.2.2. The House The plan layout of the house was a longitudinal sofa, defined as a spatial distribution hall on the central axis, and the rooms symmetrically located at the either sides of the sofa at the ground and first floors (Figure 4).

At the ground floor, one of the shorter sides of the sofa in the east provides the entrance from the street through a niche below a bay-window, which was located at the first floor and called jumba (Figures 2B and 4). The other side across the entrance gave way to the courtyard below a balcony at the first floor (Figures 4A). The connection between the two floors was provided through the wooden stairs at the southeast corner where a service space on the ground floor and a toilet on the first floor were also included (Figure 4). The entrance to the basement, located $1.5 \mathrm{~m}$ below the courtyard level, was provided by the stairs descending through a niche-like space between the house and the cloth-drying building (Figures 3 and 5A). 


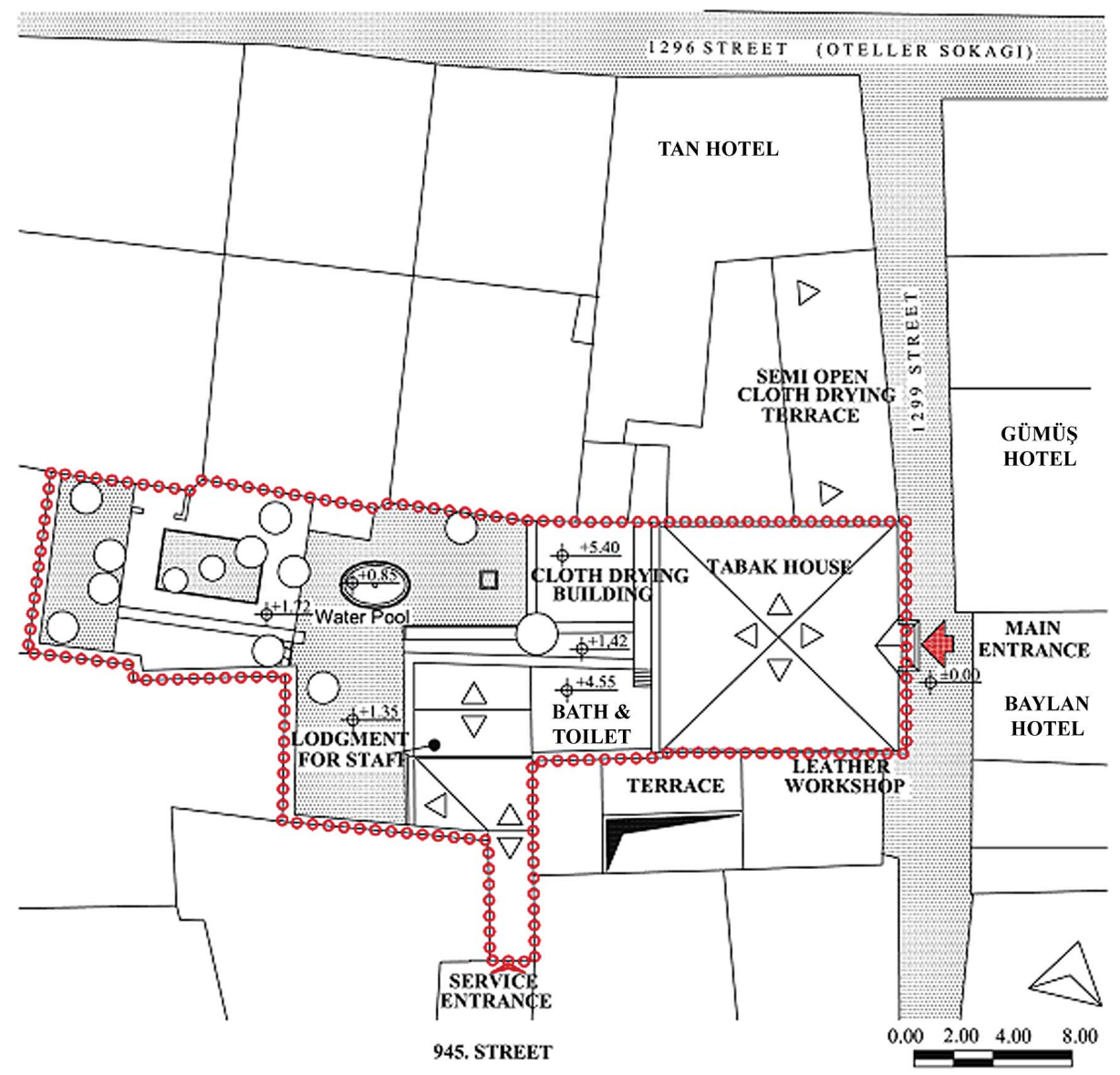

Figure 3. Illustration of the location of the Tabak House (modified from the measured drawings provided by the Department of Architectural Restoration, Izmir Institute of Technology, Izmir, Turkey) (figure is provided in color online).

The basement was composed of two spaces, Space 1 and Space 2, which were almost equal in size and character (Figures 5B and 6). These spaces were connected through a brick-vaulted narrow passage. The basement was entered through a metal door which was $1.05 / 0.95 \mathrm{~m}$ in dimensions and placed at the north edge of the Space 1 . Facing to the street, there were four window-openings, each of which was $0.95 / 0.95 \mathrm{~m}$ in dimensions. They were placed approximately $0.30 \mathrm{~m}$ above the earthen basementground. The bottom level of these windows corresponded to a level of a few centimeters above the street coated with asphalt (Figure 2B). One of the two windows of each space on this wall was filled with brick (Figure 6). In addition to these openings, there were two more openings at the west wall of the Space 2, but they were filled with rubble stone when the bath/toilet building was attached to the house (Figure 6).

The structure of the house reflects the characteristics of the composite system which combined stone/brick masonry and wood construction techniques. The exterior leaves of the north and south walls above the ground floor level were composed of brick 


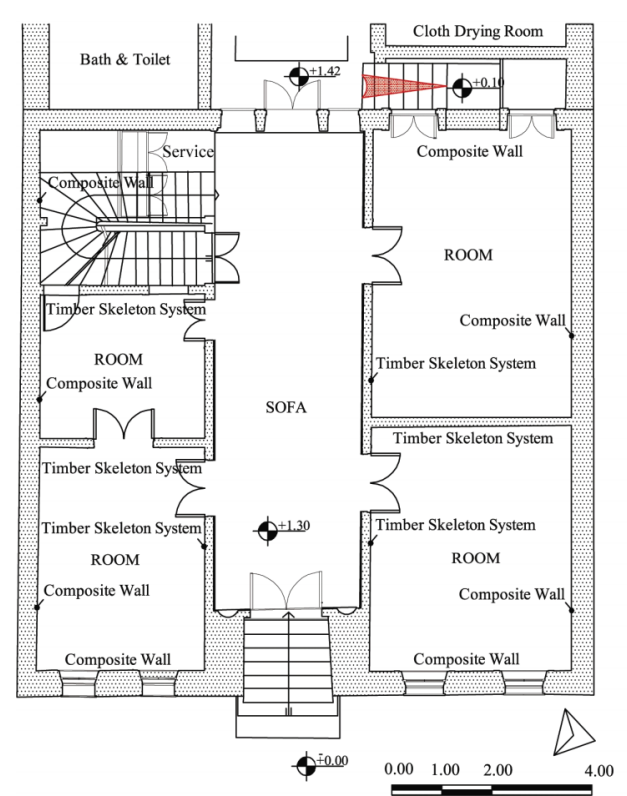

[a]

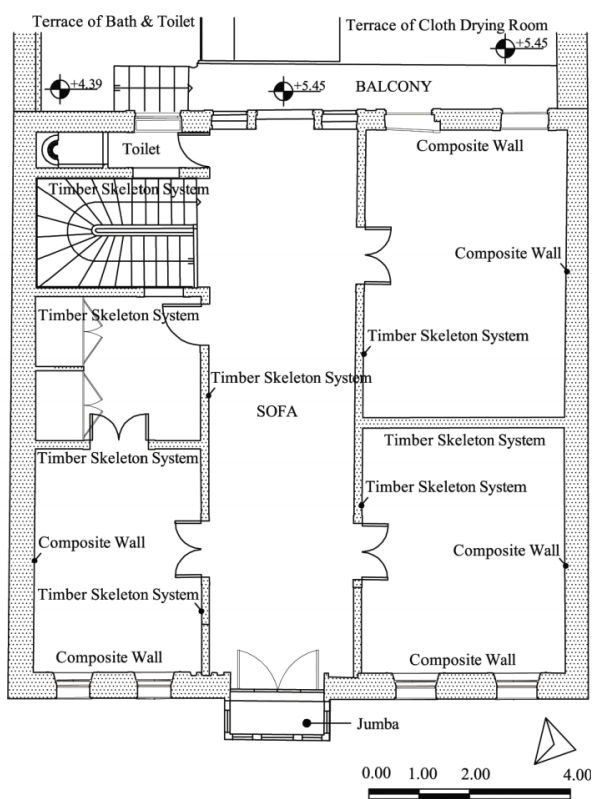

[b]

Figure 4. Plans of A) the ground floor and B) the first floor (modified from the measured drawings provided by the Department of Architectural Restoration, Izmir Institute of Technology, Izmir, Turkey) (figure is provided in color online).

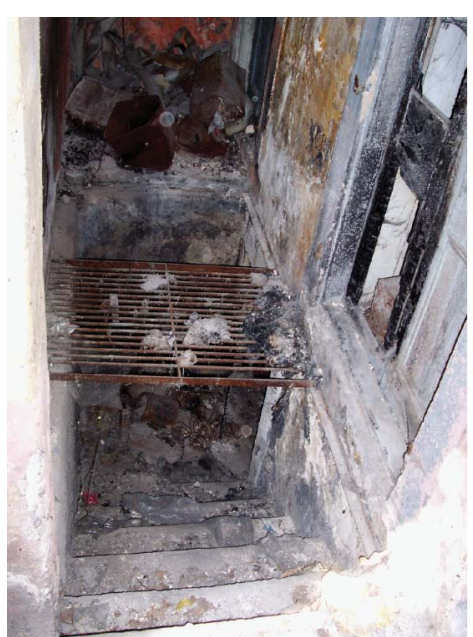

[a]

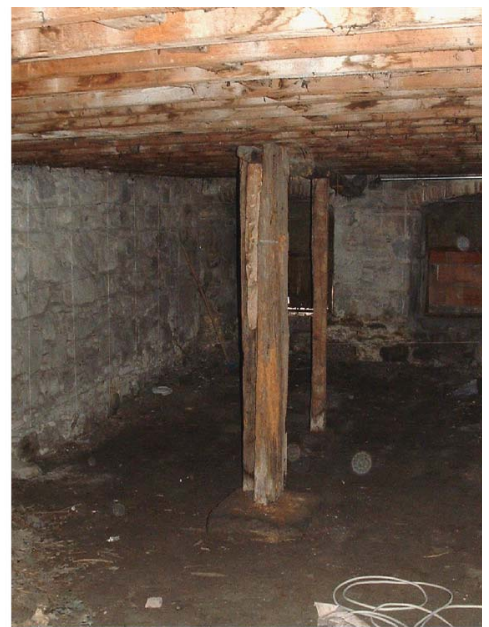

[b]

Figure 5. Photographs of A) the basement entrance niche and B) the stairs leading to the basement (figure is provided in color online).

with the width and length of $21 \pm 2 \mathrm{~cm}$ and the thickness of $3.5 \mathrm{~cm}$, while their interiors were of wood frame with rubble infill and rendered with lime plaster. Half brick units were also available in brick courses. The thickness of mortar joints was $2-2.5 \mathrm{~cm}$. 


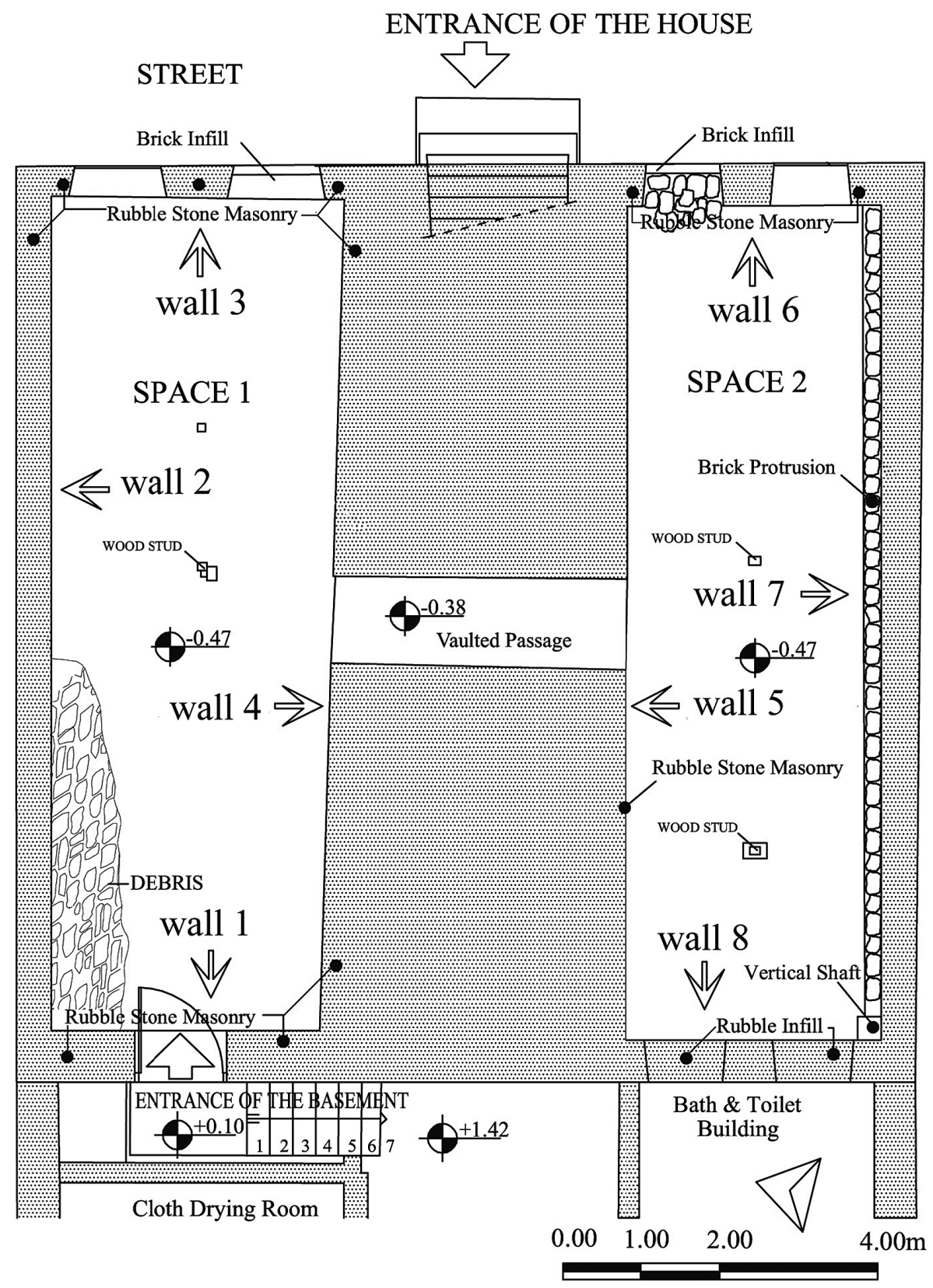

Figure 6. Basement floor plan (modified from the measured drawings provided by the Department of Architectural Restoration, İzmir Institute of Technology, Izmir, Turkey).

The exterior walls of the house and the longitudinal walls of the sofa on both floors support the structure. The walls of the basement, on which the wood beams of the ground floor rested, were constructed of ruble stone masonry (Figure 5B). The separation walls between the rooms on both sides of the sofa at the ground and first 
floors were supported by the wood studs that were erected on the single footings in the basement. The footings were made out of cut stone blocks (Figure 5B).

The rubble masonry walls of the basement, composed of andesite stones and lime mortar, were approximately $1.90 \mathrm{~m}$ high from the ground level and $0.50 \mathrm{~m}$ deep. In addition to stone, brick was partially used in the vault of the connection passage between the Spaces 1 and 2, relieving arches above the windows and a foundation-like brick protrusion from the south wall of the Space 2 (Figure 6). The flooring material of the basement was compacted earth.

\section{SURVEY AND EXPERIMENTS}

\subsection{Measurements of Moisture Content and Temperature of the Wall Surfaces}

To take systematic moisture readings, a grid system, for which each module was approximately $0.50 / 0.50 \mathrm{~m}$ in dimensions, was formed on the wall surfaces of the basement by stretching ropes. Each wall was numerated on clockwise direction (Figure 6). The same grid was also used as the base for the maps to show the moisture and thermal profile of the wall surfaces.

As the scale on IRT images showed, the temperature difference on the surfaces was not more than $4^{\circ} \mathrm{C}$ in most cases. Thus, similar to the moisture maps, two ranges such as $22^{\circ}-23^{\circ} \mathrm{C}$ and $23^{\circ}-24^{\circ} \mathrm{C}$ were determined for the mapping of surface temperatures to express the gradation from cool to warmer zones. Each range is expressed by the tones of purple. As the application of IRT technique requires (Grinzato et al., 1998; 2002; Balaras and Argirou, 2002; Avdelidis and Moropoulou, 2004; Barreira and Freitas, 2007), the thermal map of each longitudinal wall was obtained by the evaluation of several IR panoramic shots along and perpendicular to the wall surface due to the narrow widths of the Spaces 1 and 2. Therefore, the distorted IRT perspective-images presented together with the normal photographs here are not accurate but mere rough images of the walls taken at the beginning of the detailed scanning of each wall.

\subsection{Determination of the Indoor and Outdoor Climatic Conditions}

2.2.1. Indoor Climatic Conditions Relative humidity, ambient and dew point temperatures, and air flow in the basement space were detected through the hygroscopic and thermal measurements by the use of testo with its software testo Comfort v3.2 (Testo AG, Lenzkirch, Germany). The results have been presented in diagrams obtained from the software (Figure 12).

2.2.2. Outdoor Climatic Conditions The meteorological data, obtained from the annual reports provided by the General Directorate of the State Meteorological Service İmir Regional Station situated to the east of the house at $6 \mathrm{~km}$ air-distance, contained monthly averages of the ambient and dew point temperatures, and relative humidity recorded at 7. $7 \mathrm{AM}, 2 \mathrm{PM}$, and $9 \mathrm{PM}$. In addition to temperatures and relative humidity, the frequency of the direction and velocity of the prevailing winds, and rainfalls were also included in the data for the past 2 years, 2004 and 2005.

The data belonging to indoor and outdoor climate were delineated in the diagrams. The data, which covered a 'one week-period' before each survey day, 
were also presented in diagrams to evaluate the likely effects of the most-recent outdoor conditions on the measurements during the survey days.

\subsection{Material Sample Collection}

The samples of stone, brick, mortar and plasters, each of which weighs approximately $50-60 \mathrm{~g}$ and $25 \mathrm{~cm}$ in depth from wall surfaces were collected by a conventional technique - simply, using chisel and hammer with care not to cause further damage. A high-speed driller was not used because of the excessive heat and cooling water both produced during the drilling and cause changes in the in-situ characteristics' of the materials. Sample from the earthen ground was collected from $10-15 \mathrm{~cm}$ depth where the stratum was relatively hard. The collected samples were immediately packed and sealed in polyvinyl bags for the laboratory analyses to determine their moisture and water-soluble salt contents, porosity and water absorption capacities in the laboratory.

The nomenclature used for the samples indicated the type of the material, such as $\mathrm{M}$ being mortar, S stone, B brick and PL plaster. The digits indicated the number of the samples. The spots of the collection were indicated on the drawings of the walls (Figure 7).Together with the granular sample of soil, the samples of plaster (PL) and the brick (B2) were analyzed only for their moisture and soluble salt contents and types because they were extremely fragile.

\subsection{Laboratory Analyses}

2.4.1. Determination of Moisture and Soluble Salt Content of the Materials Before the determination of the physical properties, the samples were removed from their sealed packs and immediately weighed $\left(\mathrm{m}_{\mathrm{wet}}\right)$. The samples were then dried in an oven at $60^{\circ} \mathrm{C}$ until they reach at a constant weight $\left(\mathrm{m}_{\mathrm{dry}}\right)$. The reason for such a mild temperature to dry out the samples was to avert likely decompositions in their crystal structure. Their moisture contents ([MC] \% in Mass) were calculated by the following formula:

$$
\operatorname{MC}(\%)=\left[\left(\mathrm{m}_{\mathrm{wet}}-\mathrm{m}_{\mathrm{dry}}\right) / \mathrm{m}_{\mathrm{dry}}\right] * 100
$$

The analyses of water-soluble salt contents of the samples were carried out by the measurement of electrical conductivity of the solutions of samples which were obtained by dissolution of finely powdered $1 \mathrm{~g}$ of sample in distilled water. The percentages of the salt contents were calculated by the following formula (Black, 1965);

$$
\text { Salt content }(\%)=\left[\left(\mathrm{A} \times \mathrm{V}_{\mathrm{sol}}\right) / 1000\right] \times\left(100 / \mathrm{M}_{\mathrm{sam}}\right)
$$

Where;
A is Salt concentration $(\mathrm{mg} / \mathrm{l})=640 \times \mathrm{EC}(\mathrm{mS} / \mathrm{cm})$;
EC is Electrical conductivity $(\mathrm{mS} / \mathrm{cm})$;
$\mathrm{V}_{\text {sol }}$ is Volume of the solution $(\mathrm{ml})$; and
$\mathrm{M}_{\text {sam }}$ is Weight of the sample (mg). 


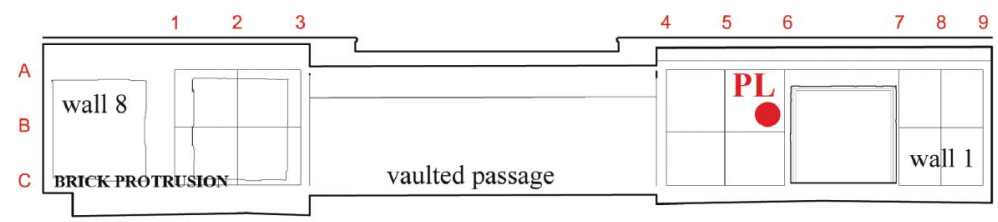

[a]

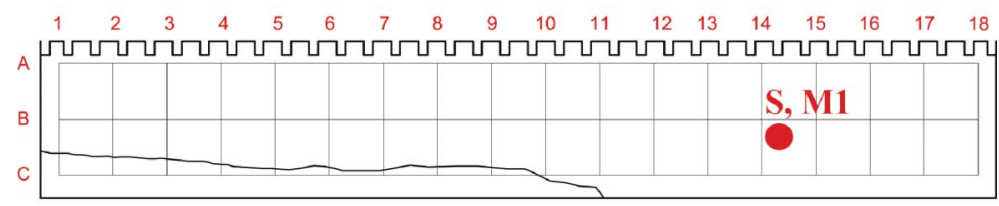

[b]

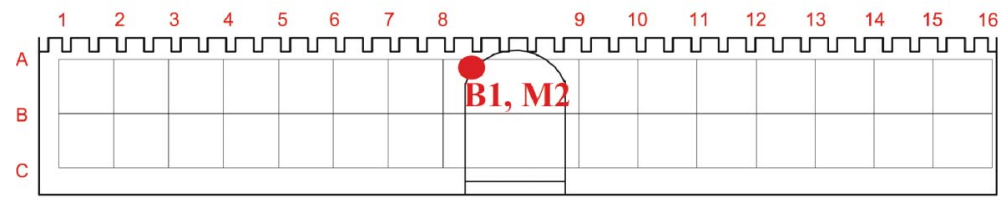

$[\mathrm{c}]$

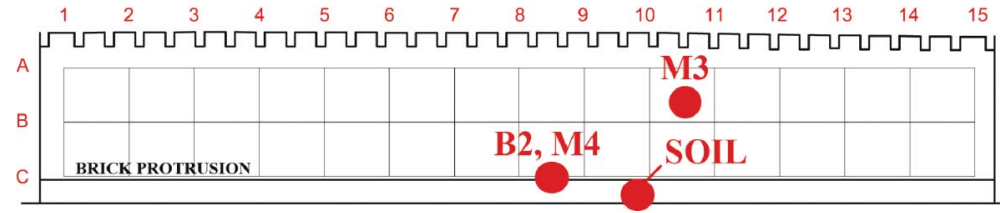

[d]

Figure 7. Illustration of the material sample collection: A) walls \#1 and \#8, B) wall \#2, c) wall \#4, and d) wall \#7 (PL, plaster; S, stone; B, brick; M, mortar) (figure is provided in color online).

The moisture and soluble salt contents of the materials were presented in the same diagrams. In addition to their content, the anion parts, such as $\left(\mathrm{Cl}^{-}\right)$, nitrate $\left(\mathrm{NO}_{3}{ }^{-}\right)$, sulfate $\left(\mathrm{SO}_{4}{ }^{2-}\right)$ and phosphate $\left(\mathrm{PO}_{4}{ }^{2-}\right)$ of the most common soluble salts were also determined by spot tests to estimate their possible sources. The assessment was done visually according to the degree of the changes in color and precipitations in the sample solutions (Teutonico, 1986). The results are presented in Table 1.

\subsubsection{Determination of Porosity and Water Absorption Capacity of the}

Materials For the determination of basic physical properties, each dried sample was separated into three pieces, of approximately $15-20 \mathrm{~g}$, and weighed $\left(\mathrm{m}_{\mathrm{dry}}\right)$. The saturation of the samples in distilled water was carried out in a vacuum oven. The weights of the water-saturated samples were recorded as saturated weights $\left(\mathrm{m}_{\mathrm{sat}}\right)$. The weight of saturated samples was also measured in water and recorded as the Archimedes weight $\left(\mathrm{m}_{\mathrm{arch}}\right)$ of the samples. All weights were measured with the sensitivity of $0.01 \mathrm{~g}$ and they were used in the calculation of porosity, density, and water absorption capacity of the samples as follows (RILEM, 1980; Teutonico, 1986):

$$
\mathrm{P}(\% \mathrm{vol})=\left[\left(\mathrm{m}_{\mathrm{sat}}-\mathrm{m}_{\mathrm{dry}}\right) /\left(\mathrm{m}_{\mathrm{sat}}-\mathrm{m}_{\mathrm{arch}}\right)\right] * 100
$$




$$
\begin{gathered}
\mathrm{D}\left(\mathrm{g} / \mathrm{cm}^{3}\right)=\left(\mathrm{m}_{\text {dry }}\right) /\left(\mathrm{m}_{\text {sat }}-\mathrm{m}_{\text {arch }}\right) \\
\mathrm{WAC}(\% \mathrm{vol})=\left[\left(\mathrm{m}_{\text {sat }}-\mathrm{m}_{\text {dry }}\right) /\left(\mathrm{m}_{\text {dry }}\right)\right] * 100
\end{gathered}
$$

where WAC is water absorption capacity. Together with the moisture and soluble salt contents, the physical properties of the materials are expressed in Table 1.

\section{RESULTS AND DISCUSSION}

\subsection{The Outdoor Climate Conditions in the Years 2004 and 2005}

The meteorologic data revealed that the probability of the occurrence of outdoor condensation was relatively higher in January, February, November and December, especially between midnight and early mornings due to the lower ambient and dew point temperatures which were quite close and high relative humidity compared with those values recorded at noon times (Figure 8). With respect to their frequencies, the winds from the west (W) and south-southeast (SSE) seemed to be dominant throughout the years 2004 and 2005 (Figure 9A).

As Figure 9B shows, the strong winds blew from the SW, S, and SSE. The SSE winds were supposed to be effective on the outside drying conditions through the front facade of the house. However, a hilltop, on which the citadel Kadifekale is located approximately $1.5 \mathrm{~km}$ towards the SE, formed a topographic obstacle in receiving the dominant winds of the region from SSE (Figures 1B, 1C, and 3). In addition, the taller hotel buildings and other buildings across the very narrow street (not more than $4 \mathrm{~m}$ wide) seemed to prevent the basement of the house from receiving the winds from the northeast (NE) and east-northeast (ENE) directions (Figures 3 and 9). The west (W) winds were not also effective on drying due to the attachments of the cloth-drying and bath/toilet buildings built in 1960s blocking the west facade of the basement (Figure 3).

Review of the distribution of the rainfall in the past 2 years (2004 and 2005) revealed that the rain was effective in winter, autumn and partially in spring (Figure 10). The same Figure shows that the amount of rain in 2005 was higher, especially in February, October and November than the rainfalls in the previous year. This finding may indicate that the rain penetration into the house, in particular, through the partially collapsed roof, accelerated the damages in the upper floors in the past year of 2005 .

\subsection{The Results of the Surveys}

3.2.1. Outdoor and Indoor Conditions Outdoor conditions in the 1-week-periods before each survey day proved that condensation did not take place outside since the dew point temperatures were not reached (Figure 11). In both survey days, the relative humidity in the basement $(70 \%-73 \%)$ which was higher than the outdoor humidity $(39 \%-60 \%)$ (Figure 12). Indicating improper ventilation which provoked the dampness problem, the air movement in the basement was considerably low in both survey days $(0.01 \mathrm{~m} / \mathrm{s})$ (Figure 12). 


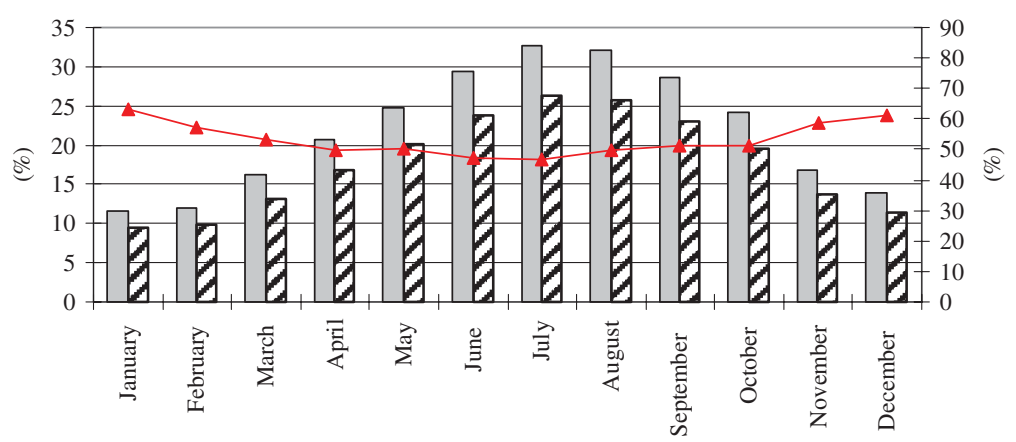

$\square \mathrm{T} \rightleftharpoons \mathrm{Td} \longrightarrow \mathrm{RH}$

[a]

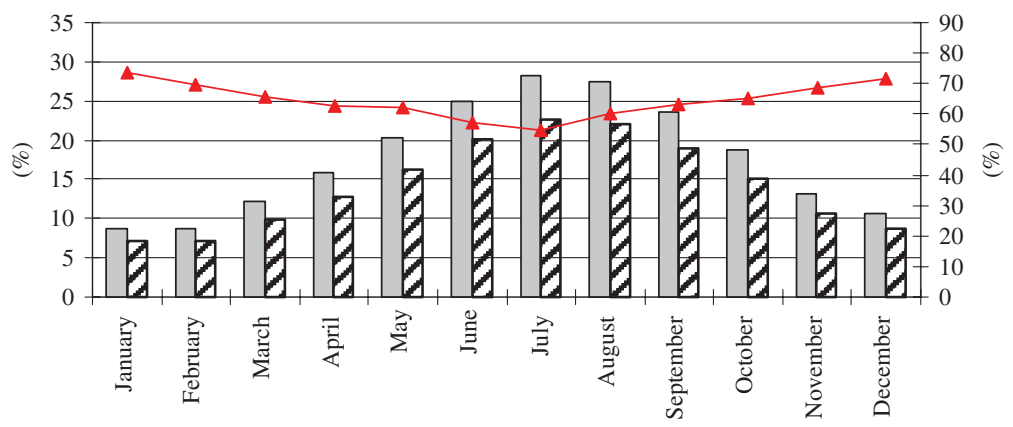

$\square \mathrm{T} \boldsymbol{\mathrm { Td }} \rightarrow \mathrm{RH}$

[b]

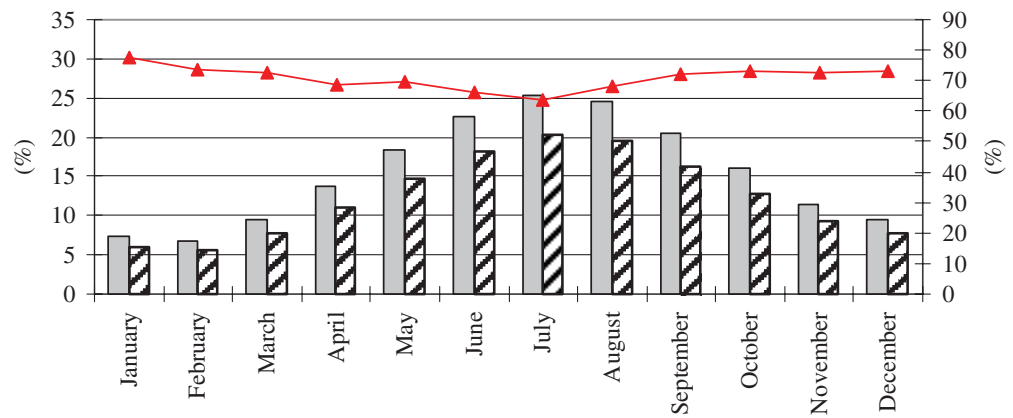

$\square \mathrm{T} ש \mathrm{Td} \backsim \mathrm{RH}$

[c]

Figure 8. Graph of the monthly averages of the ambient temperature $\left(\mathrm{T}^{\circ} \mathrm{C}\right)$, dewpoint temperature $\left(\mathrm{Td}^{\circ} \mathrm{C}\right)$ and relative humidity (RH) at A) 7:00 AM, B) 2:00 PM, and C) 8:00 PM in the years 2004 and 2005 (data from the General Directorate of the State Meteorological Service, Izmir Regional Station, Turkey) (figure is provided in color online). 


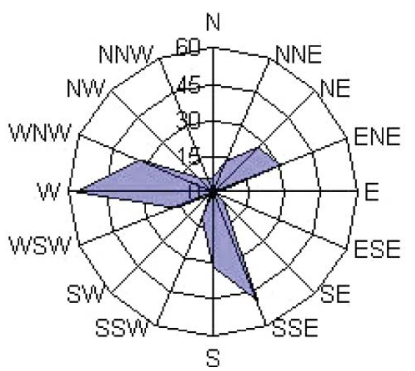

[a]

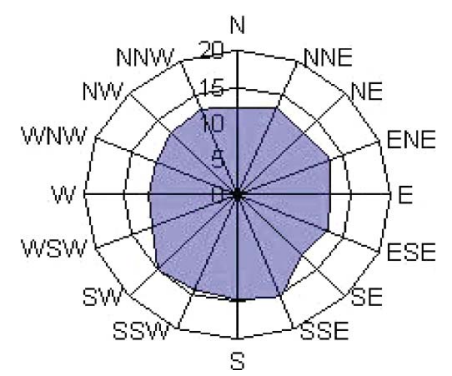

[b]

Figure 9. The directions of A) the frequency and B) the velocity $(\mathrm{m} / \mathrm{s})$ of the prevailing winds in the years 2004 and 2005 (data from General Directorate of the State Meteorological Service, İzmir Regional Station, Turkey) (figure is provided in color online).

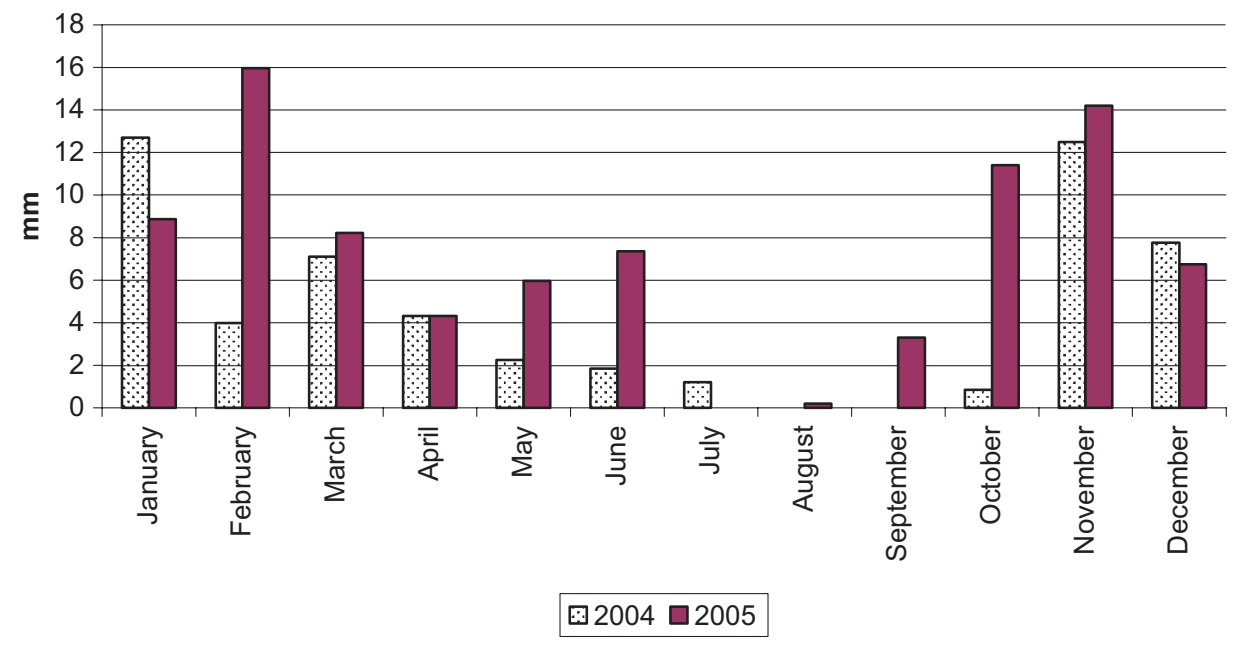

Figure 10. Graph of the monthly averages of the rainfall distribution in the years 2004 and 2005 (data from General Directorate of the State Meteorological Service, İzmir Regional Station, Turkey) (figure is provided in color online).

Regarding condensation in the basement, the September 23 survey showed that condensation did not occur since the difference between ambient and dew point temperatures were high enough. However, indoor conditions on the December 2 proved that the condensation was possible (Figure 12).

3.2.2. Moisture Contents and the Surface Temperatures of the Walls Regarding moisture content measurements and IRT scanning results are concerned, most of the moisture seemed to be raised from the ground (Figures 13 and 14).In addition to the dampness from the ground, the rain water penetration caused by the rainfalls on September 17, which was proven by the wet beams that appeared on the IRT image, 


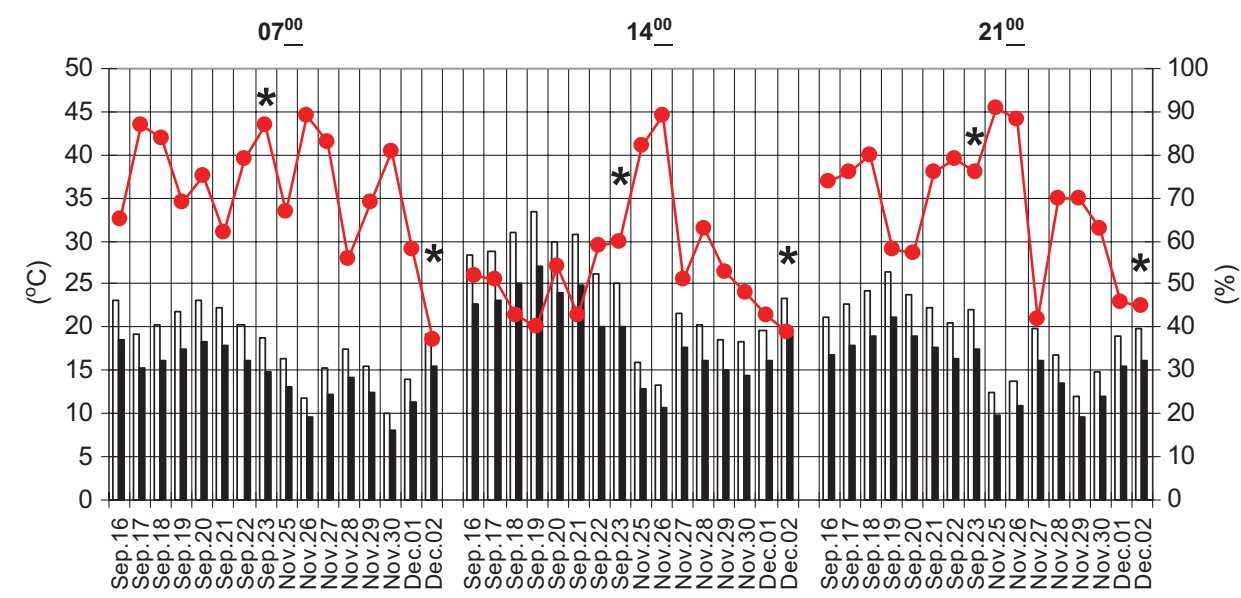

$\square \mathrm{T}^{\circ} \mathrm{C}=\mathrm{Td}^{\circ} \mathrm{C} \longrightarrow \mathrm{RH}(\%)$ * Survey days

Figure 11. Graph of the outdoor temperature and humidity conditions during the 1-week period before each survey day in $2005\left(\mathrm{~T}^{\circ} \mathrm{C}\right.$, normal temperature; $\mathrm{Td}^{\circ} \mathrm{C}$, dewpoint temperature; $\mathrm{RH}$, relative humidity (data from General Directorate of the State Meteorological Service, İzmir Regional Station, Turkey) (figure is provided in color online).

and rainfalls on November 25-27 seemed to affect the dampness that was detected by the survey on December 2 (Figures 15 and 16).

As it was explained in the evaluation of the outdoor and indoor conditions, condensation did not take place during the survey times. However, some cool but relatively dry zones are the indicative of the regions that are prone to condensation when the dew point temperature was reached and the relative humidity increased between midnight and early morning (Figure 17).

The cooling of these zones was likely caused by air flow through the gaps of the window sashes and the gaps at the upper edge of the masonry walls where the wood beams and planks of the ground floor rested. Such a cool zone was also observed around the vertical shaft through which the former baked-clay sewage disposal pipe passed (Figure 18).

\subsection{Results of Laboratory Analyses}

3.3.1. Moisture and Water-Soluble Salt Contents of the Materials Soluble salt content of the materials increased with their moisture contents which were calculated by their wet and dry weights. The highest amount of moisture and salt content was found in the soil sample. It was followed by the moisture and salt contents of brick (B2) and its jointing mortar (M4) from the foundation-like brick bonds protruded from the lower part of the rubble masonry wall \#7 (Figures 6, 7D, and 19).

The soluble salt contents of the other mortars (M2, M3) were also high. Regardless of their calculated-moisture contents, they showed extremely high values, in fact, almost always $100 \%$ during the moisture measurements with moisture meter. Such an extremely high conductance can be attributed to the nature of the mortars in 


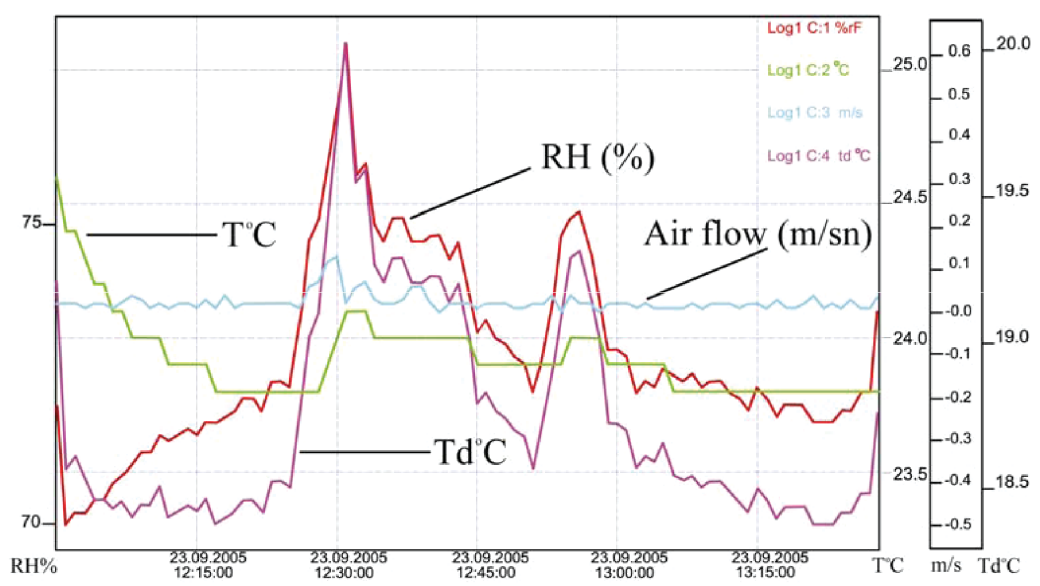

[a]

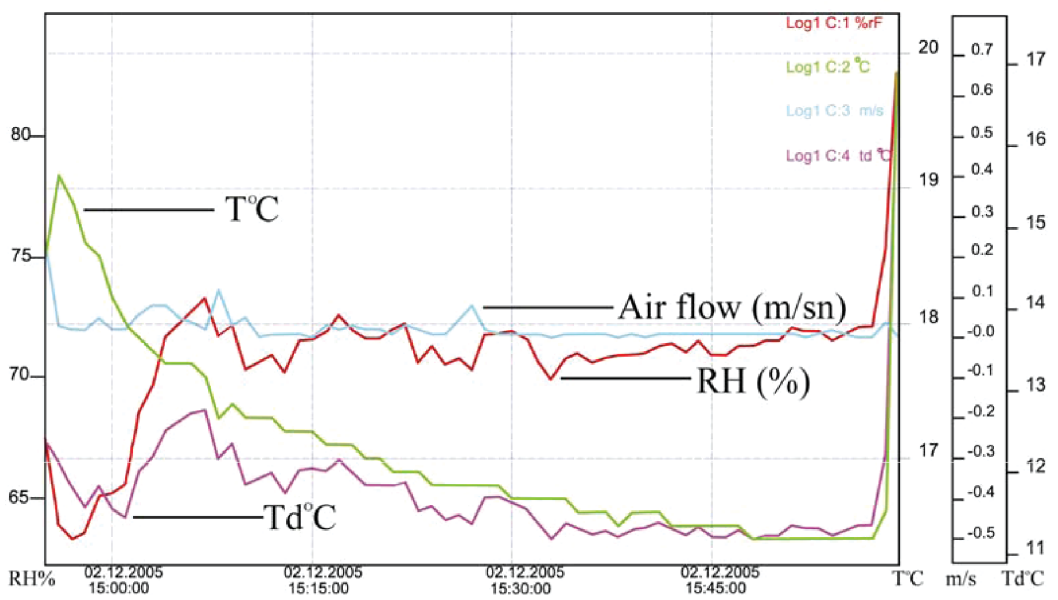

[b]

Figure 12. Graph of A) the indoor climate conditions on September 23, 2005 (the sudden jumps in the peaks were the moments when the infrared thermography survey team of three people was passing near by Testo equipment); B) and on December 2, 2005 (redrawn from the original Testo outputs) (figure is provided in color online).

which lime was used as binder. Unlike other salts, calcium carbonate does not dissolve in water easily. However, such a high salinity may be due to the more soluble bicarbonate likely formed by the reaction of sufficient amount of carbon dioxide and the water (Teutonico, 1986) which was permanently present in the basement atmosphere and the walls. Although not measured during the surveys, the presence of such amount of carbon dioxide in the basement atmosphere was possible because of the polluted air that penetrated and probably trapped in winter times due to the insufficient ventilation. Because of an uncertainty, mortars were not included in the moisture survey of the walls by electrical conductivity measurements. Instead, their 


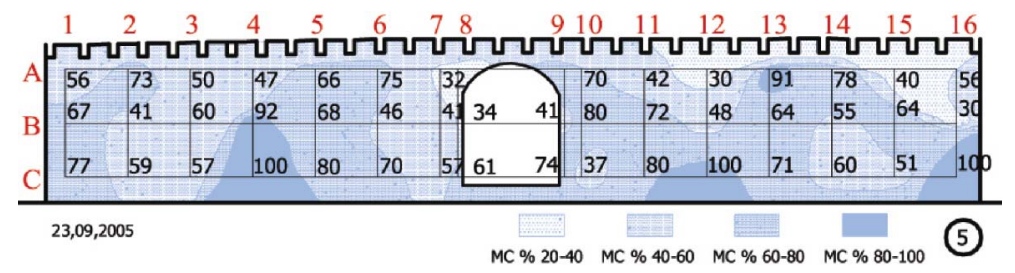

[a]

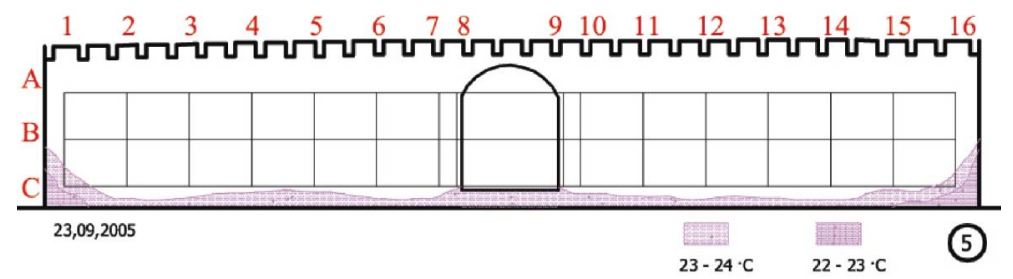

[b]

Figure 13. A) moisture and B) thermographic map of the wall \# 5 indicating rising damp (September 23, 2005) (figure is provided in color online).

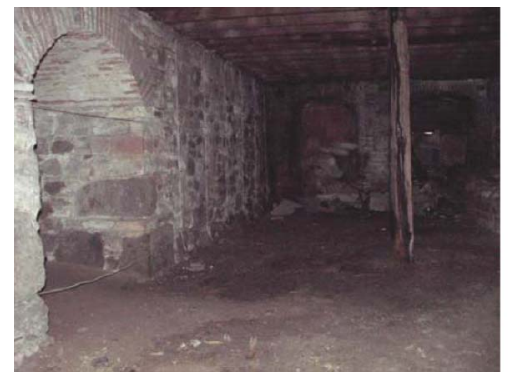

[a]

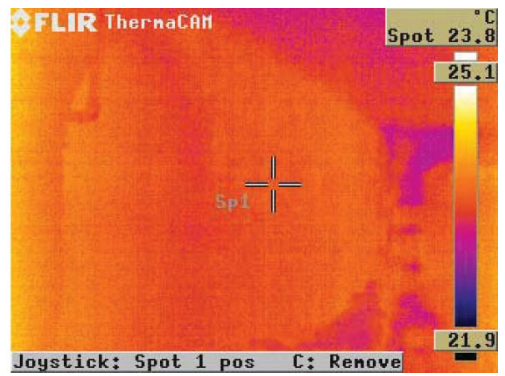

[b]

Figure 14. A) Photograph and B) infrared thermographic image of the wall $\# 5$ of the basement showing rising damp (September 23, 2005) (figure is provided in color online).

calculated-moisture contents were evaluated in terms of the relations between moisture and the physical properties of masonry materials of the basement.

3.3.2. Salt Types Detected by Spot Tests Spot tests for the determination of the anion parts of the salts showed that the salts of $\mathrm{Cl}^{-}$and $\mathrm{NO}_{3}{ }^{-}$formed the major group particularly in the soil (Table 1). The high amounts of $\mathrm{Cl}^{-}$and $\mathrm{NO}_{3}{ }^{-}$salts are the evidences of the leaks from the sewage disposal system of the house and attached buildings when the system was active in the past.

Other than the soil, the $\mathrm{SO}_{4}{ }^{2-}$ contamination in the construction materials is possibly due to the leaks from the dissolved (by the rain penetration from the damaged roof) gypsum ornaments, such as the cornices framed the topmost edges of the rooms at the upper floors or due to the polluted air trapped in winter times. $\mathrm{PO}_{4}{ }^{2-}$ was not found in any of the samples. 


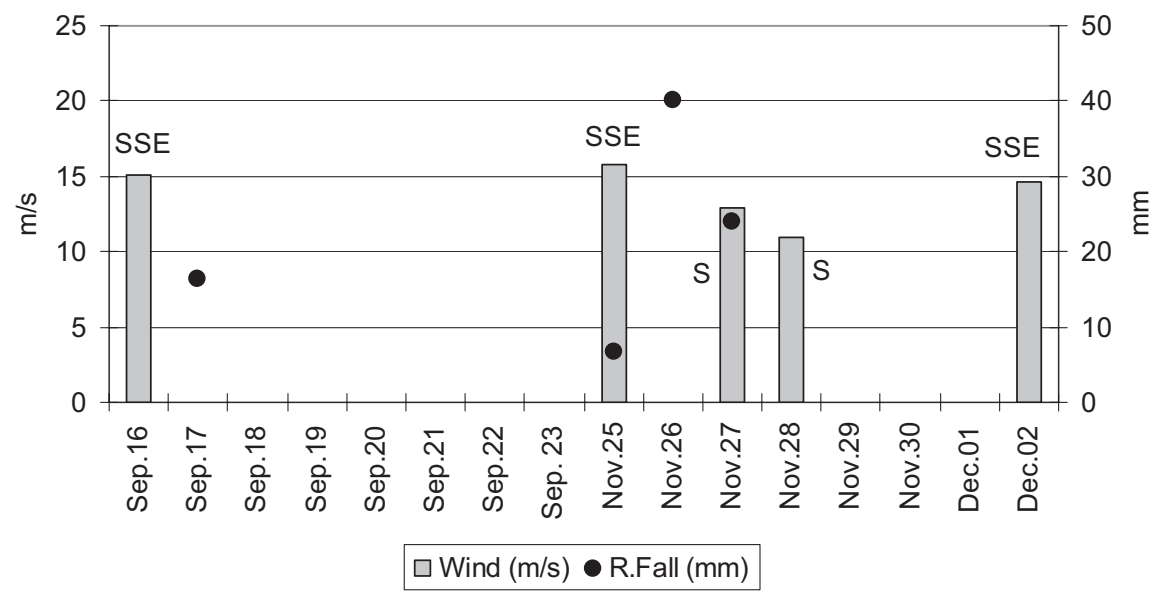

Figure 15. Graph of the velocity $(\mathrm{m} / \mathrm{s}$ ) and directions (south and south-southeast) of the winds, and rainfall $(\mathrm{mm})$ during the 1-week-period before each survey day in 2005 (data from General Directorate of the State Meteorological Service, İzmir Regional Station, Turkey).

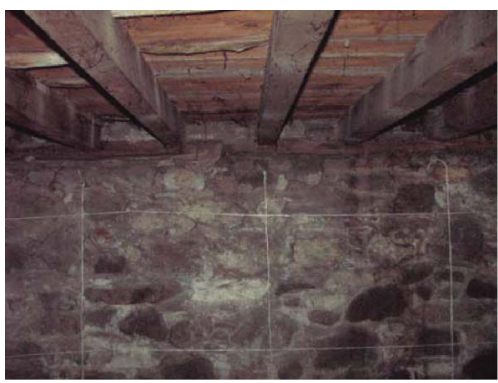

[a]

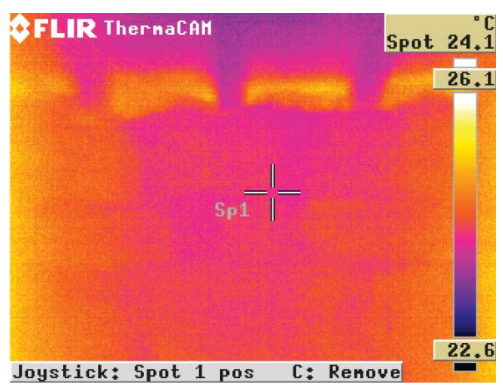

$[\mathrm{b}]$

Figure 16. A) Moisture and B) infrared thermographic map of the wall \#7 indicating cool zones (December $2,2005)$ (figure is provided in color online).

3.3.3. Physical Properties of the Materials The porosity values of the mortars varied between $48 \%-45 \%$. The porosity of brick (B1) was $31 \%$, followed by the porosity of stone $(\mathrm{S})$, which was $16 \%$, being the least. Parallel to the porosity values, water absorption capacity of the mortars varied within a small range, which was not more than 5\% (Figure 19).

The comparison between the porosity $(\mathrm{P})$, water absorption capacity and calculated-moisture content indicated to what extent the accessible pores of the materials were saturated with water. Following the soil sample, the brick (B2) and its jointing mortar (M4) both collected from the spots close to the ground had relatively higher MC and salt content, respectively. They were followed by the MC and salt content of the mortars of M3, M2, M1, brick (B1), stone (S) and plaster (PL) in descending order (Figure 19) as the heights of their collection spots from the ground increased (Figure 7). Indicating the reason and initial source of the 


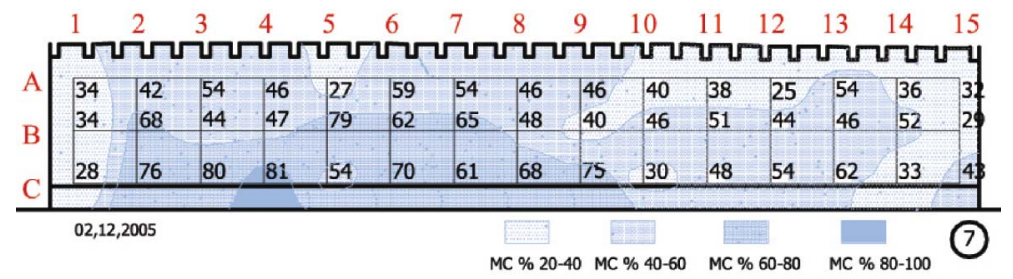

[a]

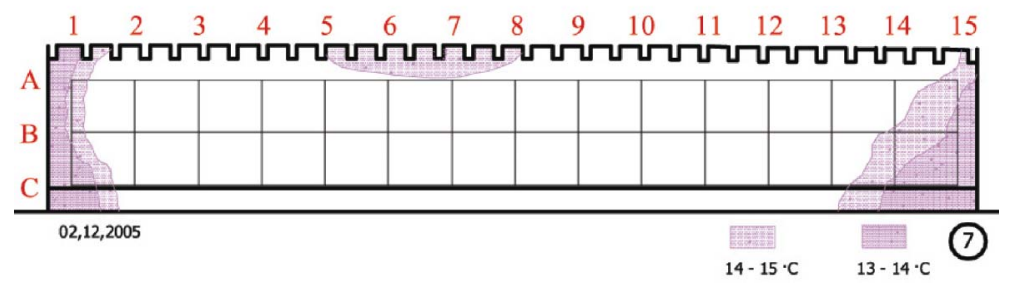

[b]

Figure 17. A) Moisture and B) infrared thermographic map of the wall \#7 indicating cool zones (December 2,2005 ) (figure is provided in color online).

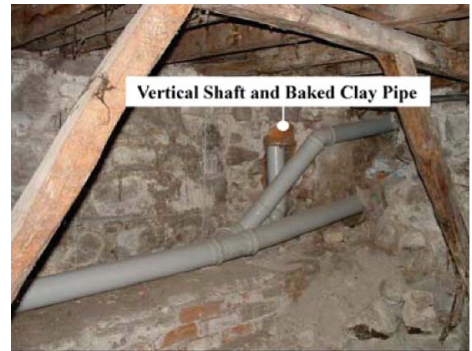

[a]

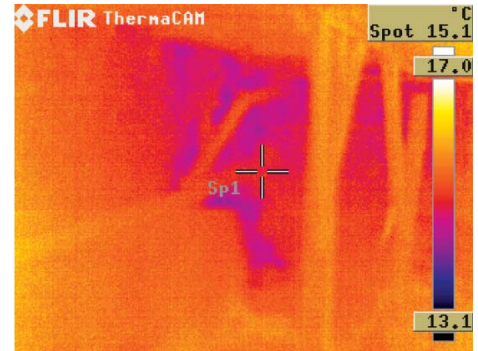

[b]

Figure 18. A) Photograph and B) infrared thermographic image of wall \#7, showing cool zone around the vertical shaft (December 2, 2005) (figure is provided in color online).

dampness, the existence of hygroscopic salts in the walls should also be considered as permanent moisture sources for the walls because they absorbed water from the ambient air which was almost permanent and usually high in the basement. However, as far as the long time of abandonment and inactive water and sewage disposal systems are concerned, such a rising trend in the calculated moisture and salt contents of the materials lead one to think of the possibility of water absorption from the soil ground at present besides the steady absorption from the humid air. Although the sampling, IRT and conductometric surveys were carried out at the surface and/or slightly deeper points from the surface of the walls, the similarity in the conditions of moisture content is probable in the depth of the walls when the long time of moisture absorption is considered.

Among the materials, the extreme saturation of stone (S) was remarkable (Figure 19). Despite its relatively low porosity and water absorption capacity, the 
Table 1. The results of spot tests for the anion parts of soluble salts in the materials

\begin{tabular}{lcccc}
\hline Samples & $\left(\mathrm{Cl}^{-}\right)$ & $\left(\mathrm{NO}_{3}{ }^{-}\right)$ & $\left(\mathrm{SO}_{4}{ }^{2-}\right)$ & $\left(\mathrm{PO}_{4}{ }^{2-}\right)$ \\
\hline Soil & +++++ & +++++ & + & - \\
M1 & ++++ & +++ & + & - \\
M2 & ++++ & ++++ & + & - \\
M3 & ++ & ++++ & ++ & - \\
M4 & ++++ & ++++ & +++ & - \\
B1 & ++++ & ++ & ++++ & - \\
B2 & ++++ & +++ & ++++ & - \\
S1 & ++++ & ++ & +++ & - \\
PL & ++ & ++ & ++ & - \\
\hline
\end{tabular}

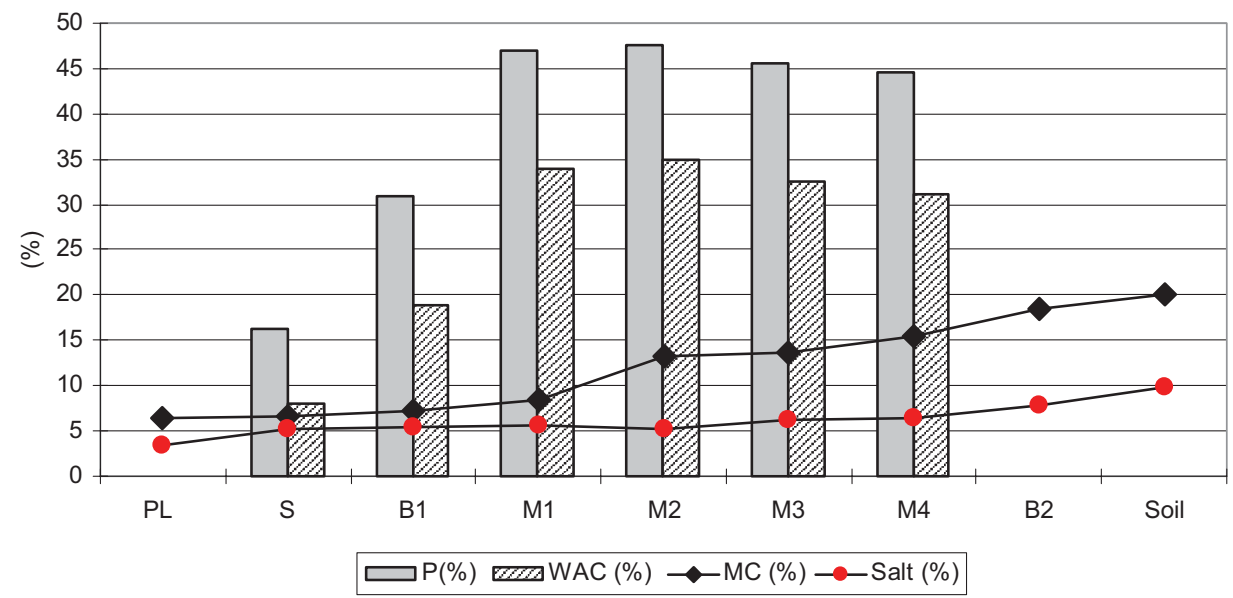

Figure 19. Graph of the porosity (P), water absorption capacity (WAC), moisture (MC) and the watersoluble salt contents of the materials (S, stone; B, brick; M, mortar; and PL, plaster; B2, PL, and soil samples were analyzed only for their moisture and soluble salt contents) (figure is provided in color online).

saturation of the accessible pores of the andesite stone which formed the major portion of the basement masonry, may indicate that its pore structure was composed of small-sized (capillary) pores, as the materials having capillary pores of this type draw water faster, but dries slower when compared to those with larger pores (Schaffer, 2004), i.e. as brick and mortars. This implied the future difficulty in providing the sufficient drying conditions in the basement.

3.3.4. Evaluation of the Location and Architectural Characteristics The Tabak House faced newly constructed taller buildings that have been serving as hotels, such as the Baylan Hotel and Gümüş Palace. These buildings prevented the lower parts of the front facade from receiving sunlight until noon while hindering the NE and ENE winds from sufficiently drying the house (Figure 3 ).

The attachment of the structures such as the toilet and bath building, and the building for cloth drying were the later applications that prevented the basement from drying through its rear facade (Figure 3). 
In addition, the north sidewall of the house was neighbor to a semi-open laundry and cloth-drying terrace used by Tan Hotel (Figure 3). The faulty details at the intersection of the north facade wall and the canopy (made of corrugated galvanized sheet which was fixed on steel pipes at the terrace), were the sources of rain water leaks and disposed water from cloth washing. The concrete floor slab of the terrace which was covered with screed without any water protection along the intersection line with the house was the second source of rainwater penetration on this side (Figure 20).

The situation at the south side of the house which was occupied by a leather workshop and its open terrace was similar to the situation described for the north side. The chimney fixed to the south wall of the house, and the intersection with the terrace slab and this wall without proper details seemed to cause water leaks into the house (Figures 3, 20C, and 20D).

On the front side of the house, it was seen that the bottom edges of the basement windows were raised just a few $\mathrm{cm}$ above the asphalt surface of the street without any sufficient barrier (Figure 2B). Such a faulty detail also gave way to the penetration of the rainwater splashes into the basement through the gaps of the windows. The walls, \#3 and \#6, on which these windows were placed could not be

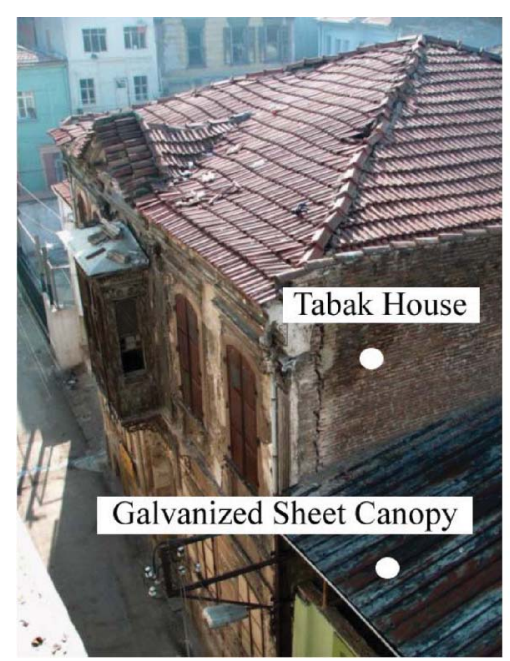

[a]

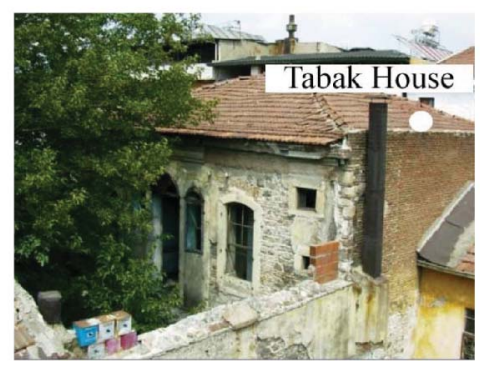

[c]

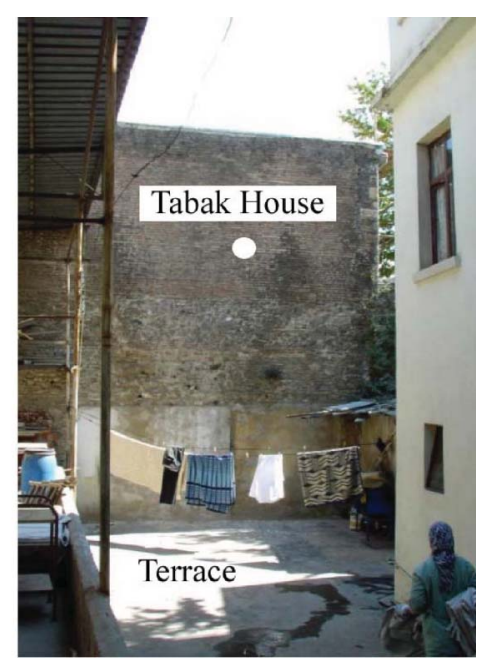

[b]

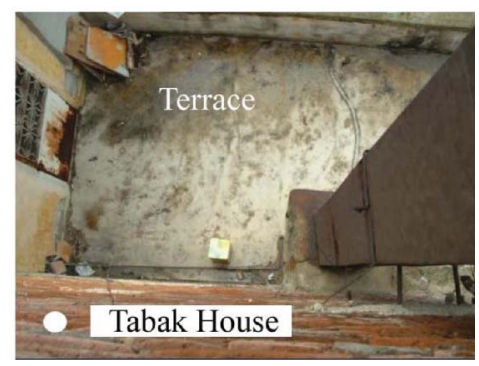

[d]

Figure 20. Photographs of A) and B) the cloth-drying terrace view of Tan Hotel, C) the chimney, and D) the terrace of the leather workshop (figure is provided in color online). 
scanned by IRT due to the leaks of daylight from the gaps at the windows. However, the permanent existence of moisture at the interior faces of these walls was detected by moisture readings.

Concerning the dampness problem, the shallow height of the ceiling, which was not more than $1.90 \mathrm{~m}$, and permanently closed door and windows of the basement seemed to be important obstacles for the evacuation of the humid and contaminated air.

\section{CONCLUSION}

The IRT scanning and conductometric measurements on the wall surfaces proved that moisture was concentrated at the lower parts of the wall surfaces. The calculated moisture and soluble salt contents, and the detection of salt types in the materials showed that the source of dampness was soil ground. At present, if the dampness were not due to the leaks from the sewage disposal systems or water installations from the buildings around, investigation of the ground water is recommended. The study also revealed that:

- Causing damages in the fabric of the structures through efflorescence when dried, hygroscopic salts provided permanent source of dampness, thus, creating discomfort for the occupants. The salts must be removed with proper cleaning methods. If this approach is not practically possible, the salts must be isolated and kept in dry conditions by proper insulation details against moisture intake as much as possible.

- Despite the heterogeneous nature of the masonry structures, IRT and moisture measurements were proved to be helpful techniques for a quick survey of a qualitative estimation of the present and potential sources of dampness in the house studied. However, such dampness studies should also be supplemented by the combination of other techniques such as microwave or georadar tests and thorough material analyses if more accurate results are expected for more critical cases.

- Faulty details should be improved with suitable techniques without harming the authentic features of the historic building under concern.

- In addition to aesthetic and ethical considerations, decisions for the new buildings in historic environments should also carefully consider the location and environmental climate that surrounds the historic buildings to be preserved.

\section{ACKNOWLEDGEMENTS}

The authors are highly indebted to Professor Zafer İlken and Research Assistant Barış Budak of the Department of Mechanical Engineering for their guidance in using IRT camera, and to the Department of Architectural Restoration of İzmir Institute of Technology (IYTE) for permitting use of the measured drawings of the house.

\section{REFERENCES}

Avdelidis, N. P., and Moropoulou, A. 2003. Emissivity considerations in building thermography. Infrared Energy and Buildings 35:663-667.

Avdelidis, N. P., and Moropoulou, A. 2004. Applications of infrared thermography for the investigation of historic structures. Journal of Cultural Heritage 5:119-127.

Avdelidis, N. P., Moropoulou, A., and Theoulakis, P. 2003. Detection of water deposits and movement in porous materials by infrared imaging. Infrared Physics \& Technology 44:183-190. 
Balaras, C.A., Argirou, A. 2002. Infrared thermography for building diagnostics. Energy and Buildings 34:171-183.

Barreira, E., and de Freitas, V. P. 2007. Evaluation of building materials using infrared thermography. Construction and Building Materials 21:218-224.

Binda, L., Saisi, A., Ludwig, N., Maeierhofer, C., Leipold, S., and Schaurich, D. 1998. Combination of non-destructive testing methods for the characterization of moisture content and distribution in a historic brick wall. Available at http://www.beniculturali.polimi. it/documenti/ricerche/42_050119033059_8r4s.pdf (accessed November 2008).

Black C. A. 1965. Methods of Soil Analysis, Part 2. Madison, WI: American Society of Agronomy.

Clark, M. R., McCann, D. M., Forde, M. C. 2003. Application of infrared thermography to the non-destructive testing of concrete and masonry bridges. NDT\&E International 36:265-275.

Coleman, G. R. 1999. Use of electrical moisture meters. Available at: http://www.building preservation.com./Use $\% 20$ of $\% 20$ moisture $\% 20$ meters\%20.html (accessed September 6, 2007).

Coleman, G. R. 2000. Distribution of moisture and soluble salts in masonry. Available at: http://www.buildingpreservation.com/Moisture\%20and\%20salts.htm (accessed September 6, 2007).

Gayo-Moncó, E., and de Frutos, J. 1997. Interference filters as an enhancement tool for infrared thermography in humidity studies of building elements. Infrared Physics \& Technology 38:251-258.

Gayo-Moncó, E., and de Frutos, J. 1998. Hydric processes associated with saline solutions, studied by means of selective infrared thermography. Cement and Concrete Research 28:1165-1177.

Grinzato, E., Bison, P. G., and Marinetti, S. 2002. Monitoring of ancient buildings by the thermal method. Journal of Cultural Heritage 3:21-29.

Grinzato, E., Marinetti, S., Bison, P.G., Concas, M., and Fais, S. 2004. Comparison of ultrasonic velocity and IR thermography for the characterization of stones. Infrared Physics and Technology 46:63-68.

Grinzato, E., Vailov, V., and Kauppinen, T. 1998. Quantitative infrared thermography in buildings. Energy and Buildings 29:19.

Kääriänen, H., Rudolph, M., Schaurich, D., Tulla, K, and Wiggenhauser, H. 2001. Moisture measurements in building materials with microwaves. NDT\&E International 34:389-394.

Meola, C., Di Mario, R., Roberti, N., and Carlomagno, G. M. 2005. Application of infrared thermography in geophysical methods for defect detection in architectural structures. Engineering Failure Analyses 12:875-892.

Moropoulou, A. Avdelidis, N. P., Koui, M., Aggelopoulos, A., and Karmis, P. 2002. Infrared thermography and ground penetrating radar for airport pavements assessment. NDT\&E International (18)1:37-42.

Quarles, S. L. 2008. Physical limitations of moisture meters. Forest Products Society. Available at: http://alcor.concordia.ca/ raojw/crd/reference002010.html (accessed November, 2008).

RILEM, 1980. Tentative Recommendations, Commission 25 - PEM, Recommended tests to measure the deterioration of stone and to asses the effectiveness of treatment methods. Materials and Structures / Matériaux et Construction 13(73):173-253.

Schaffer, R. J. 2004. The Weathering of Natural Building Stones. London, England: Donehead Publishing.

Teutonico J. M. 1986. A Laboratory Manual for Architectural Conservators. Rome, Italy: International Centre for the Study of the Preservation and Restoration of Cultural Property (ICCROM).

Wiggenhauser, H. 2002. Active IR-applications in civil engineering. Infrared Physics \& Technology 43:233-238.

Wirahadikusumah, R., Abraham, D. M., Iseley, T., and Prasanth, R. K. 1998. Assessment technologies for sewer system rehabilitation. Automation in Construction 7:259-270.

Yardım, B. 2006. Examination of Dampness Problems of a Historic House. İzmir Institute of Technology Master's Thesis, Department of Architectural Restoration, İzmir, Turkey. 